\title{
Modelling of a Polarization Insensitive UWB FSS with Band Stop Response
}

\author{
Sapna BIJIMANZIL ABDULKAREEM, Srivatsun GOPALAKRISHNAN
}

Dept. of Electronics and Communication Engineering, PSG College of Technology, Coimbatore-641004, India

sapna.psmi@gmail.com,gsn.ece@psgtech.ac.in

Submitted July 28, 2020 / Accepted March 14, 2021

\begin{abstract}
This paper presents a compact ultra-wideband frequency selective surface (FSS) with band stop response. The proposed single layer FSS is printed on FR-4 substrate with a unit cell periodicity of $0.138 \lambda_{0} \times 0.138 \lambda_{0}$, corresponding to its lowest operating frequency. The developed FSS exhibits stable response for plane waves with normal and oblique incidence with TE and TM polarization for angles varying from $0^{\circ}$ to $60^{\circ}$. The FSS offers $-10 \mathrm{~dB}$ bandwidth of $141 \%$ covering the entire ultra-wideband frequency range from $2.39 \mathrm{GHz}$ to $13.67 \mathrm{GHz}$. The structural parameters are optimized, and an equivalent circuit is modelled to analyze the performance of FSS. The simulated results are validated by the measured values.
\end{abstract}

\section{Keywords}

Frequency selective surface, periodic structure, ultrawideband, bandstop, wireless communication

\section{Introduction}

The frequency selective surfaces (FSS) are 2D or 3D periodic structures exhibiting pass band or stop band filter response. Basic configurations of FSS with design concept are considered by Munk [1]. The periodic structures can be designed as spacial filters to select or reject a set of frequencies. A periodic structure with narrow band acting as a partial reflecting surface was reported by the authors [2]. The filter response of FSS differs from microwave filters in terms of its dependency in design structure, incident angle and polarization of the electromagnetic signal. Extensive survey on various FSS designs were investigated [3], [4]. Narrow, wide and ultrawideband nature of FSS fits them in diverse fields including radar cross section (RCS) reduction, electromagnetic shielding and antenna application. Single layer and dual layer FSS are reported in literature [5-7]. Simple circular slot FSS with active and passive components are capable of single or dual band operation [8], [9]. A quad band switchable FSS with pin diodes operating in ISM frequency range, improves the isolation between indoor wireless devices [10]. A miniaturized dual layer UWB FSS with dielectrics AD300A and AD600 separated by three parts of metallic elements consisting of rotated cross dipoles has $60^{\circ}$ angular stability [11]. The low-profile dual layer FSS reflector [12] covers the UWB band from 3.5 to $11.45 \mathrm{GHz}$. As FSS are designed with half wavelength, the percentage bandwidth is limited and they generate grating lobes reducing the performance in the upper band. Though multilayer FSS produce broad bandwidth, they are inefficient in terms of size and cost. FSS for RCS reduction and antenna application are discussed in earlier works [13-16]. Different polarization independent UWB FSS designs were analyzed [17-22]. Single layer dual sided FSS with UWB coverage are reported with polarization independence and higher incident angle stability [23-25]. The electromagnetic behavior of FSS structures can be analyzed using tedious mathematical modelling techniques. A relatively simple approach is to develop an equivalent circuit with inductive and capacitive reactance, which characterize the electromagnetic behavior of FSS. The LC equivalent circuit models of various periodic structures are documented [26-28]. The demand for UWB FSS with stable operation in modern high-speed communications aims at designing a novel FSS structure.

In this paper, a compact novel FSS with angular and polarization stability for UWB application is presented. Compared to the available FSS in the literature, the proposed structure has maximum percentage bandwidth on a single layer design. To operate in the UWB frequency band a combination of square and circular loop with loading strips and cross dipoles are used. With the transmission response of $-10 \mathrm{~dB}$, the designed FSS has a stable operation in TE and TM polarization for an incident signal of variable angles up to $60^{\circ}$. A simple equivalent circuit model is developed to match the response of FSS design. The FSS designs were simulated using CST microwave Studio. The frequency domain solver option of CST with Floquet's boundary conditions for unit cell geometry is chosen to compute the parametric analysis of the designed UWB FSS. The equivalent circuit values were theoretically calculated and the schematic is modelled using ADS software. The LC components of the circuit with matched terminations on either side are analyzed by tuning and the $\mathrm{S}$ parameter results in terms of reflection and transmission are plotted. 


\section{Design of the Proposed UWB FSS}

The designed FSS is aimed to operate in the FCC regulation UWB frequency band ranging from $3.1 \mathrm{GHz}$ to 10.6 GHz. The four main groups of FSS designs [1] were analyzed and the hybrid combinations of them are used to propose the new UWB FSS design. In this paper a single layer, compact UWB FSS with angular and polarization stability is designed. This reduces the cost and complexity of the design compared to multilayer designs. The proposed FSS structure is designed on FR-4 dielectric substrate with parameters $\varepsilon_{\mathrm{r}}=4.4, \tan \delta=0.025$ and height $h=1.6 \mathrm{~mm}$. The thickness $t$ of the copper conductor is $0.035 \mathrm{~mm}$.

The UWB FSS design consists of a square loop integrated with thin strips and a cross dipole convoluted circular loop to achieve ultra-wideband frequency coverage. Figure 1(a), (b) shows the top and side view of the proposed single layer unit cell FSS design. Initially a square loop with a circumference of $\lambda$ at lower frequency of $3.1 \mathrm{GHz}$ is calculated. To accommodate the upper frequency band of $10.6 \mathrm{GHz}$, a circular loop is placed at the center of the square loop. The combination of square and circular loops provides two independent bands resonating at $3.64 \mathrm{GHz}$ and $11.49 \mathrm{GHz}$ respectively. The branch loading of the loops with four narrow strips at the middle of square edges merged the resonance bands offering a bandwidth of $7.65 \mathrm{GHz}$ ranging from $2.43 \mathrm{GHz}$ to $10.09 \mathrm{GHz}$ of UWB band. To expand the higher frequency, two dipoles of $\lambda / 2$ at center frequency is placed diagonally convolving with the circular loop. This improved the bandwidth to $11.28 \mathrm{GHz}$ with $8 \mathrm{GHz}$ as the center frequency. The optimized FSS operates within the frequency band between $2.39 \mathrm{GHz}$ and $13.67 \mathrm{GHz}$. The proposed FSS unit cell has an optimized periodicity of $0.138 \lambda_{0}$ and overall height of $0.0127 \lambda_{0}$, where $\lambda_{0}$ is the free space wavelength at the lower cut off frequency. The design parameters of proposed UWB FSS unit cell are summarized in Tab. 1.

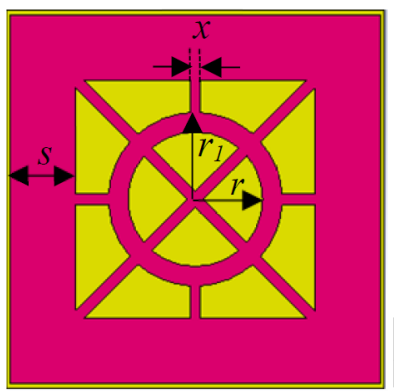

(a)

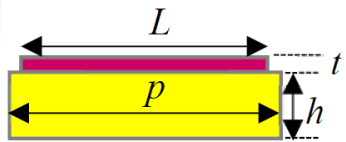

(b)
Fig. 1. The geometry of proposed UWB FSS unit cell. (a) Top view. (b) Side view.

\begin{tabular}{|c|c|c|c|c|c|c|c|}
\hline $\boldsymbol{P}$ & $\boldsymbol{L}$ & $\boldsymbol{s}$ & $\boldsymbol{x}$ & $\boldsymbol{r}$ & $\boldsymbol{r}_{\mathbf{1}}$ & $\boldsymbol{h}$ & $\boldsymbol{t}$ \\
\hline 17.4 & 17 & 3 & 0.5 & 3.1 & 4 & 1.6 & 0.035 \\
\hline
\end{tabular}

Tab. 1. Dimensions of the proposed UWB FSS unit cell in $\mathrm{mm}$.

\section{Design of the Proposed UWB FSS}

The LC equivalent circuits are simple solutions to find the resonance frequency of any complex structures. The equivalent circuits for square and circular loop FSS are based on the solutions given in [26-28]. Figure 2 shows the layout of a simple printed square and circular loop FSS with period $p$, width $w$, side length $d$ and the inter element gap between adjacent squares in a periodic array $g$. The equivalent circuit of printed square or circular loop would have a series combination of lumped inductor $L_{1}$ and capacitor $C_{1}$ connected in shunt between the free space impedance $Z_{0}$ of $377 \Omega$ as in Fig. 3(a).

The reactance $X_{\mathrm{L}}$ and susceptance $B_{\mathrm{C}}$ of (1), (2) based on [26-28] are used to solve the values of $L_{1}$ and $C_{1}$ of the equivalent circuit:

$$
\begin{aligned}
& \frac{X_{\mathrm{L}}}{Z_{0}}=\frac{d}{p} F(p, w, \lambda, \theta) \\
= & \frac{d}{\lambda} \cos \theta\left[\ln \left(\operatorname{cosec}\left(\frac{\pi w}{2 p}\right)\right)+G(p, w, \lambda, \theta)\right], \\
\frac{B_{\mathrm{C}}}{Y_{0}}= & 4 \frac{d}{p} F(p, g, \lambda, \theta) \varepsilon_{\text {eff }} \\
= & 4 \frac{d}{\lambda} \sec \theta\left[\ln \left(\operatorname{cosec}\left(\frac{\pi g}{2 p}\right)\right)+G(p, g, \lambda, \theta)\right] \varepsilon_{\text {eff }} .
\end{aligned}
$$

Here $\theta$ and $\lambda$ are the angle and wavelength of the incident signal. The correction term $G(p, w, \lambda, \theta)$ is given by

$$
0.5 \frac{\left(1-\beta^{2}\right)^{2}\left[\left(1-\frac{\beta^{2}}{4}\right)\left(A_{+}+A_{-}\right)+4 \beta^{2} A_{+} A_{-}\right]}{\left(1-\frac{\beta^{2}}{4}\right)+\beta^{2}\left(1+\frac{\beta^{2}}{2}-\frac{\beta^{4}}{8}\right)\left(A_{+}+A_{-}\right)+2 \beta^{6} A_{+} A_{-}}
$$

where $A_{ \pm}$and $\beta$ are

$$
\begin{gathered}
A_{ \pm}=\frac{1}{\sqrt{\left[1 \pm \frac{2 p \sin \theta}{\lambda}-\left(\frac{p \cos \theta}{\lambda}\right)^{2}\right]}}-1 \\
\text { and } \beta=\sin \left(\frac{\pi w}{2 p}\right) .
\end{gathered}
$$

The reactance leading to inductance of a circular loop with the same period $p$, strip width $w$ and gap $g$ of the square loop has a modified equation, as it has a variable circumference with diameter $d$ as a function of $\pi d$ compared to $4 d$ in square loop. Thus, equation (1) includes an additional factor of $\pi / 4$ for the circular loop which reduces the reactance by a factor $d / p$. The susceptance owing to the capacitor is calculated based on two adjacent circular loops acting as the parallel plates separated by the average gap distance $g_{\mathrm{a}}$, effective dielectric constant of the substrate $\varepsilon_{\text {eff }}$ and half the loop length $\pi d / 2$. This leads to a factor 


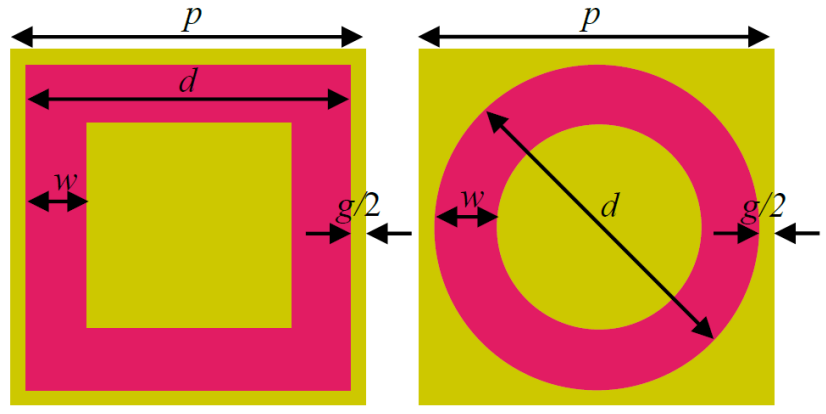

Fig. 2. The layout of square and circular loop FSS.

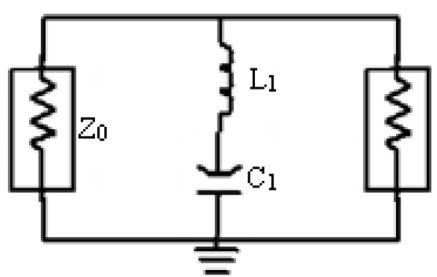

(a)

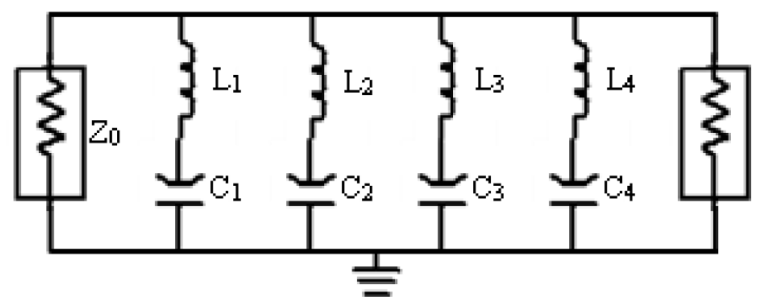

(b)

Fig. 3. The equivalent circuit of the FSS unit cells. (a) Single square or circular loop. (b) The proposed UWB FSS.

of $\pi / 2$ in (2). The modified equations for reactance $X_{\mathrm{L}}$ and susceptance $B_{\mathrm{C}}$ of circular loops are given by (3) and (4) from which the lumped inductance $L_{1}$ and capacitance $C_{1}$ are computed:

$$
\begin{gathered}
\frac{X_{\mathrm{L}}}{Z_{0}}=\frac{\pi}{4} \frac{d}{p} F(p, w, \lambda, \theta), \\
\frac{B_{\mathrm{C}}}{Z_{0}}=\frac{\pi}{2} 4 \frac{d}{p} F\left(p, g_{\mathrm{a}}, \lambda, \theta\right) \varepsilon_{\mathrm{eff}} .
\end{gathered}
$$

In (4) the average gap $g_{\mathrm{a}}$ between the circular elements is given by

$$
g_{\mathrm{a}}=p-\frac{\pi d}{4} .
$$

The outer square loop and inner circular loop forms two narrow band resonances at lower and higher frequencies of UWB range. When both loops are combined the reactance and susceptance are calculated as a parallel combination of individual elements, and the two resonance curves merge together to form a wideband response with $L_{1}, C_{1}, L_{2}$ and $C_{2}$.

In the proposed FSS design the square and circular loops are loaded with four metallic strips at the middle of the square arms and two diagonal dipoles across it. This makes two additional LC pairs. The branch loading and the mutual coupling effects further expand the operational

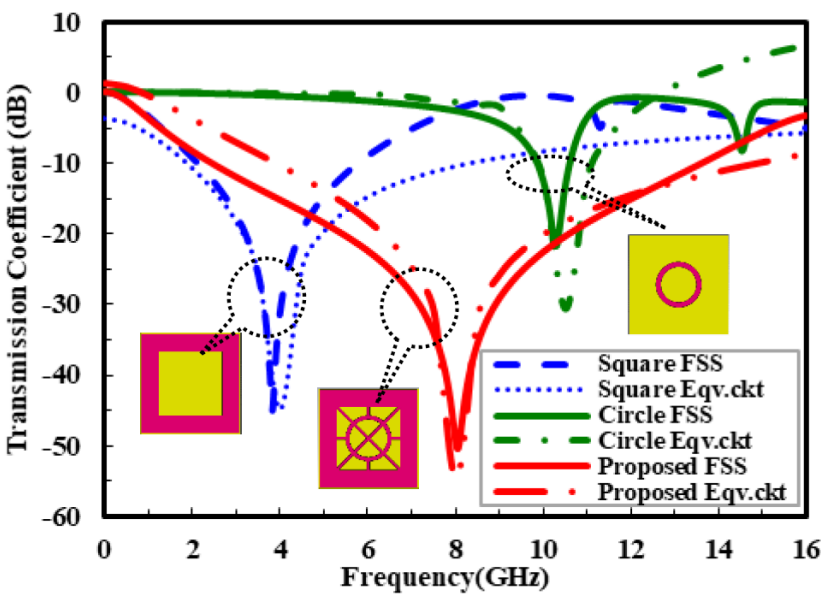

(a)

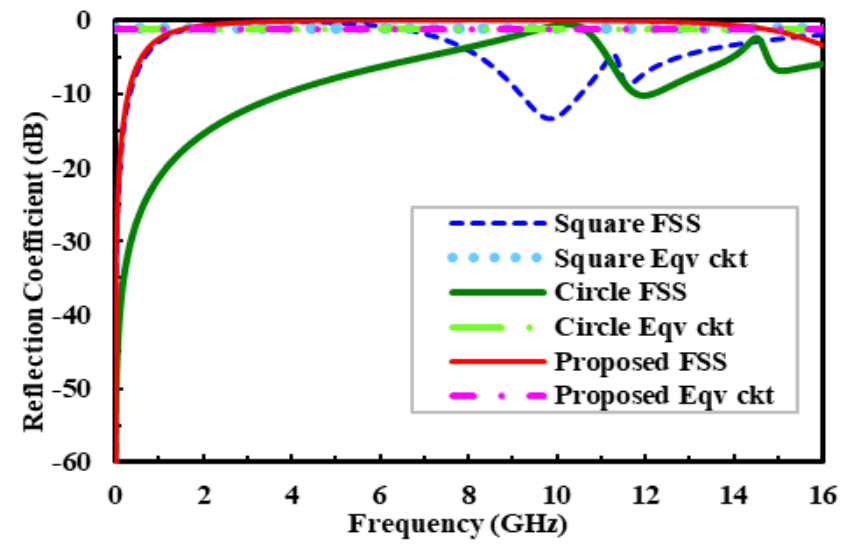

(b)

Fig. 4. The performance comparison of different FSS unit cells with their equivalent circuits: (a) Transmission coefficient; (b) reflection coefficient.

frequency band on either edge. Figure 3(b) shows the equivalent circuit of proposed UWB FSS. The values of LC pairs calculated are tuned using ADS software to match the simulated response of CST studio which also account for the coupling effects of lumped parameters.

The optimized values of equivalent LC pairs are $L_{1}=$ $2.3 \mathrm{nH}, L_{2}=2.6 \mathrm{nH}, L_{3}=2.158 \mathrm{nH}, L_{4}=2.207 \mathrm{nH}, C_{1}=$ $0.17 \mathrm{pF}, C_{2}=0.130 \mathrm{pF}, C_{3}=0.001 \mathrm{pF}$ and $C_{4}=0.16 \mathrm{pF}$. Figures 4(a), (b) represent the simulated transmission and reflection characteristics of square loop FSS, circular loop FSS and the proposed UWB FSS using CST studio along with their LC equivalent circuit response. The simulated results show good matching with the equivalent circuit response, except at higher frequencies above $12.5 \mathrm{GHz}$ for circular loop FSS which may be due to deviation in LC value on tuning than theoretically calculated.

\section{Performance Analysis of FSS}

The structural parameters $P, s, x, r$ and $r_{1}$ are optimized to accomplish the ultrawideband operation. The period $P$ of the unit cell is $17.4 \mathrm{~mm}$. The length of the square loop is maintained at $17 \mathrm{~mm}$ and the width $s$ is varied from $0.5 \mathrm{~mm}$ to $3 \mathrm{~mm}$ in steps of $0.5 \mathrm{~mm}$. The results 
show a right shift in resonance frequency with wider bandwidth. The circular loop radii $r$ and $r_{1}$ are varied from $3 \mathrm{~mm}$ to $3.5 \mathrm{~mm}$ and $3 \mathrm{~mm}$ to $5 \mathrm{~mm}$, respectively. Stable response with wider bandwidth is obtained at $r=3.1 \mathrm{~mm}$ and $r_{1}=4 \mathrm{~mm}$. The variation of the width of the cross dipoles and the strips $x$ from $0.1 \mathrm{~mm}$ to $0.7 \mathrm{~mm}$ resulted in shift of the center frequency to a higher value with increase in $x$. At $x=0.5 \mathrm{~mm}$ the center frequency is $8 \mathrm{GHz}$ with a stable response and wider bandwidth. The theoretical results and the investigation of the optimization plots reveal that the bandwidth and center frequency of the FSS is influenced with the periodic cell size and structural dimensions.

The optimized reflection and transmission response of the proposed UWB FSS for TE and TM mode are plotted in Fig. 5. The absolute value of $S_{11}$ in log magnitude format for TE and TM mode is close to zero for the entire frequency band as required. The transmission coefficient $S_{21}$ shows a value of $-50.58 \mathrm{~dB}$ at $8 \mathrm{GHz}$ frequency and is below $-10 \mathrm{~dB}$ from $2.39 \mathrm{GHz}$ to $13.67 \mathrm{GHz}$ achieving UWB operation. The phase of the reflection response varies linearly from $-180^{\circ}$ to $180^{\circ}$, within the entire frequency band from $1.389 \mathrm{GHz}$ to $15.144 \mathrm{GHz}$ as depicted in Fig. 6 .

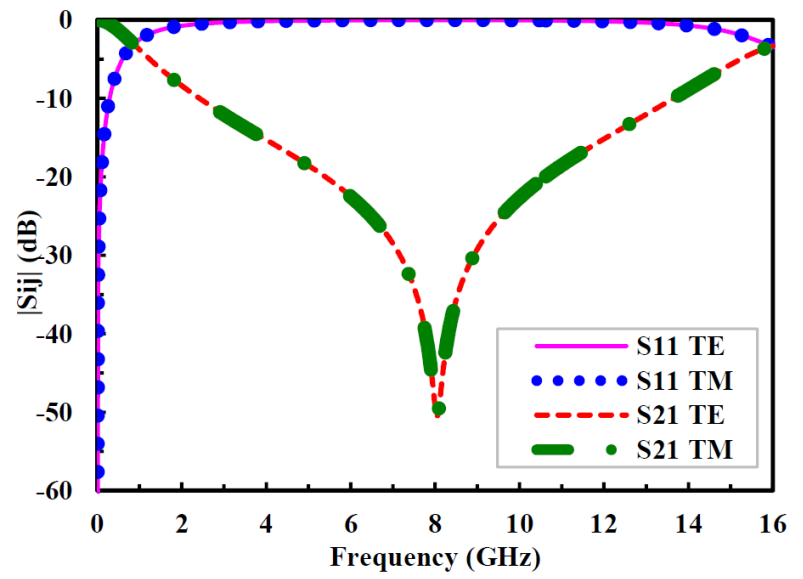

Fig. 5. The optimized performance of the proposed unit cell in terms of transmission and reflection coefficients.

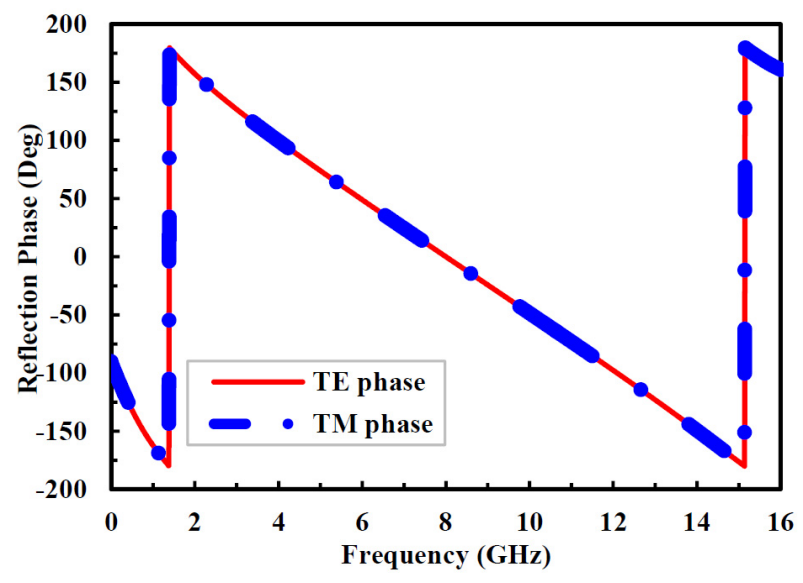

Fig. 6. The reflection phase performance of the proposed unit cell.

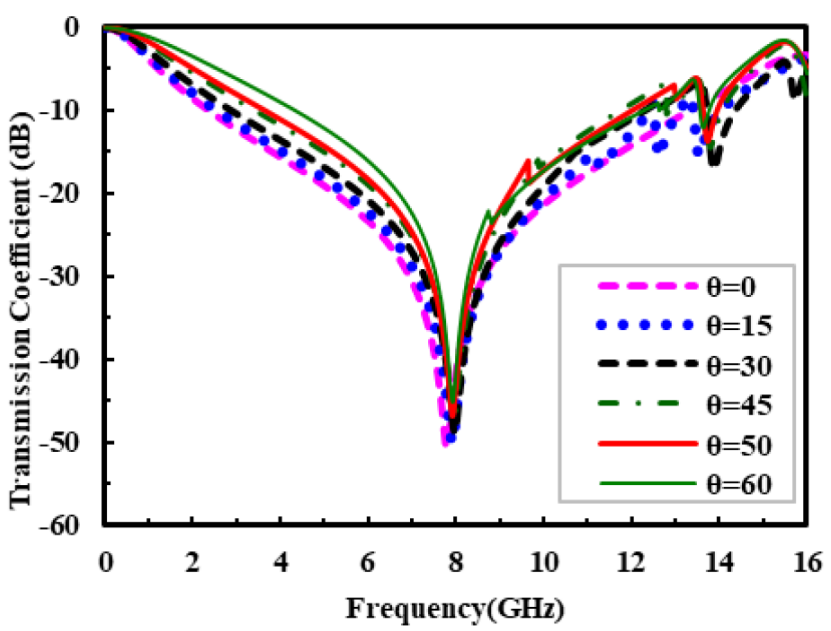

(a)

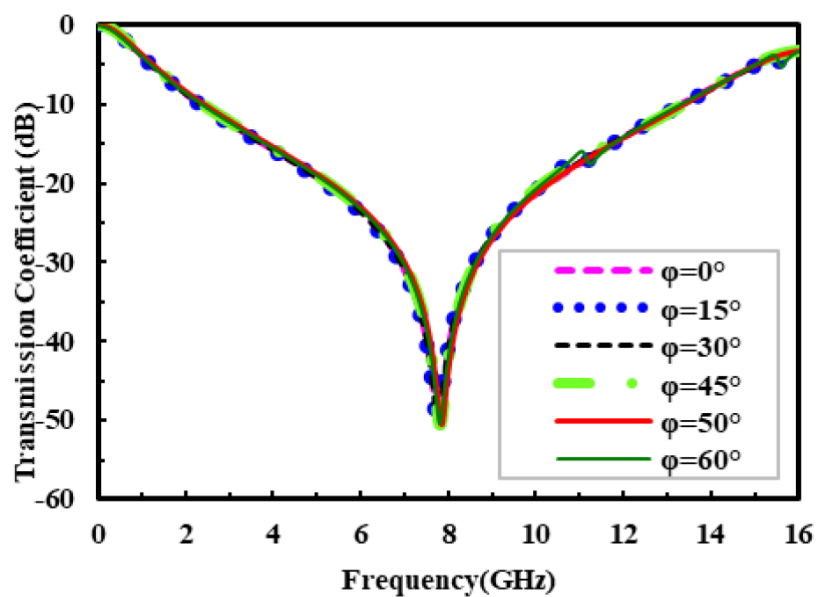

(b)

Fig. 7. Transmission characteristics of the proposed FSS for varying angles: (a) $\theta$ optimization; (b) $\varphi$ optimization.

\begin{tabular}{|c|c|c|}
\hline $\begin{array}{c}\text { Incidence } \\
\text { angle (Deg) }\end{array}$ & $\begin{array}{c}\text { Lower cut off } \\
\text { frequency at } \\
-\mathbf{1 0} \mathbf{d B} \text { (GHz) }\end{array}$ & $\begin{array}{c}\text { Upper cut off } \\
\text { frequency at } \\
\mathbf{1 0} \mathbf{d B} \text { (GHz) }\end{array}$ \\
\hline 0 & 2.39 & 13.67 \\
\hline 15 & 2.368 & 13.312 \\
\hline 30 & 2.56 & 13.08 \\
\hline 45 & 2.88 & 12.28 \\
\hline 50 & 3.4 & 12.24 \\
\hline 60 & 4.23 & 12.256 \\
\hline
\end{tabular}

Tab. 2. The cut off frequency limits of the proposed UWB FSS for different angle of incidence for TE polarization.

The response of the FSS resembles the characteristics of a band stop filter at $8 \mathrm{GHz}$ with a bandwidth of $5.2 \mathrm{GHz}$ at an attenuation level of $20 \mathrm{~dB}$.

The proposed UWB FSS is also analyzed for polarization and angular stability of the incident signal. The simulated results of transmission characteristics for various incident angles are plotted in Fig. 7(a), (b). The incident angles are varied in terms of $\theta$ and $\varphi$ from $0^{\circ}$ to $60^{\circ}$. Table 2 represents the lower and upper cutoff frequencies for different incident angle of TE polarized signal on the proposed UWB FSS with reference to $-10 \mathrm{~dB}$ level. The re- 
sults of Fig. 7 and Tab. 2 easily justify that the designed FSS is stable for different angular variations of incident signal. The FSS reflection response is stable for $\theta$ and $\varphi$ variations indicating TE and TM mode of polarization. The $\mathrm{S}$ parameters exhibit a similar response for TE and TM mode due to the symmetrical design of FSS structure. This enables the polarization independent operation of the FSS design within the operational band. The start and stop frequencies of the transmission curve with $-10 \mathrm{~dB}$ reference are $2.39 \mathrm{GHz}$ and $13.67 \mathrm{GHz}$ covering the ultra-wideband range and achieve $141 \%$ bandwidth with respect to center frequency of $8 \mathrm{GHz}$. To the best of authors' knowledge, the proposed UWB FSS has the highest \% bandwidth with polarization and incident angle stability compared to the existing similar works.

The proposed UWB FSS is also compared with same size full metal patch printed on dielectric forming capacitive grids. The reflection magnitude and phase show similar response. Though the transmission response of full metal has an upper cutoff frequency of $15.536 \mathrm{GHz}$, the proposed FSS show smooth symmetrical response with respect to the center frequency as shown in Fig. 8.

The UWB FSS is fabricated using printing technology. The fabricated FSS prototype consists of $15 \times 15$ unit cells with lateral dimension of $28 \times 28 \mathrm{~cm}^{2}$ as in Fig. 9 . The performance of the UWB FSS is tested by placing it in between two horn antennas separated by a distance of one meter apart of FSS in a partial anechoic chamber as depicted in Fig. 10. The standardized horn antenna used for measuring are, JR-12 double-ridged horn antenna and KU5086 horn antenna respectively from Verdant Telemetry from Vidyut Yantra Udyog. The measured results of FSS are plotted with frequency ranging between $0-12 \mathrm{GHz}$ due to the limitations in testing facility. The measured transmission response of fabricated FSS for incident angles at $0^{\circ}, 15^{\circ}, 45^{\circ}$, and $60^{\circ}$ are plotted in Fig. 11. The measured plots show bandstop response from $1.66 \mathrm{GHz}$ at normal incidence. For all oblique incidence the transmission response is well below the reference level of $-10 \mathrm{~dB}$.

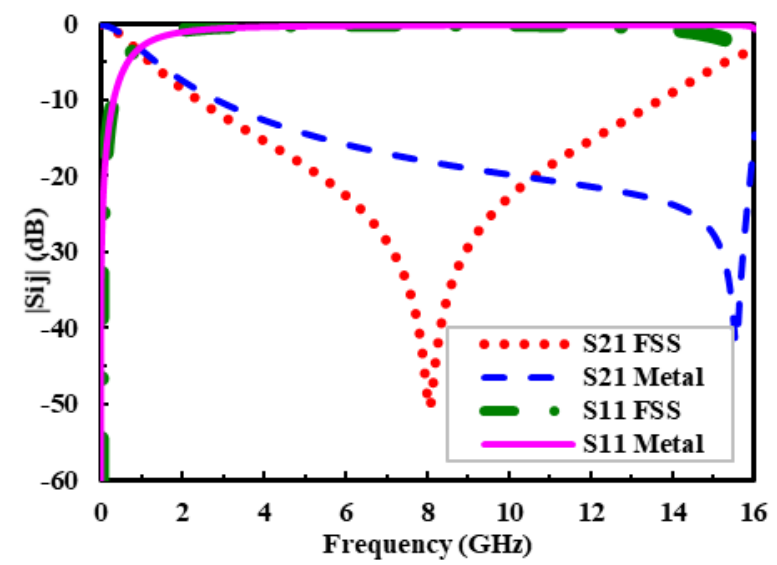

Fig. 8. The performance of the proposed FSS and metal patch in terms of transmission and reflection coefficients.

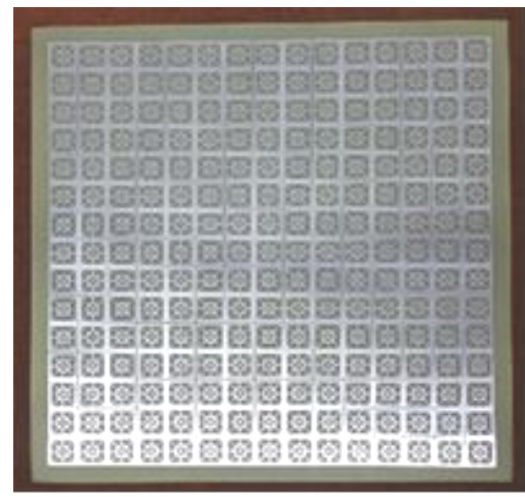

Fig. 9. The fabricated prototype of the proposed UWB FSS.

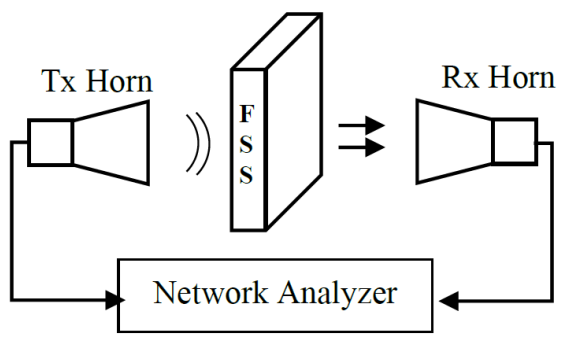

Fig. 10. The experimental setup for measuring the transmission and reflection performance of FSS.

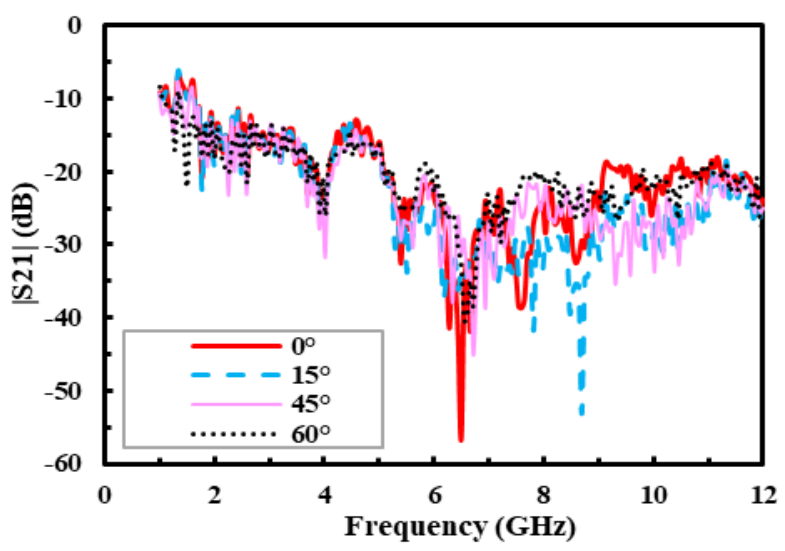

Fig. 11. The measured transmission response of the proposed UWB FSS at incident angles $0^{\circ}, 15^{\circ}, 45^{\circ}$ and $60^{\circ}$.

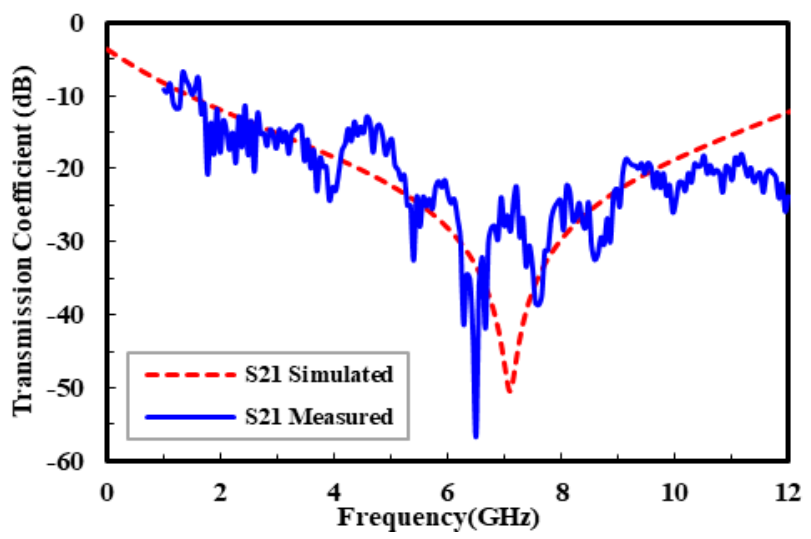

Fig. 12. Simulated and measured performance comparison of the proposed UWB FSS at normal incidence. 


\begin{tabular}{|c|c|c|c|c|c|c|c|c|}
\hline Reference & No. of layers & $\begin{array}{c}\text { Frequency } \\
\text { range } \\
\mathbf{( G H z )}\end{array}$ & $\begin{array}{c}\text { Center } \\
\text { frequency } \\
\mathbf{f}_{\mathbf{c}}(\mathbf{G H z})\end{array}$ & $\begin{array}{c}\text { \% } \\
\text { Bandwidth }\end{array}$ & $\begin{array}{c}\text { Dielectric } \\
\text { permittivity } \boldsymbol{\varepsilon}_{\mathbf{r}}\end{array}$ & $\begin{array}{c}\text { Overall } \\
\text { height }\end{array}$ & $\begin{array}{c}\text { Unit cell } \\
\text { size }\end{array}$ & $\begin{array}{c}\text { Maximum } \\
\text { angular } \\
\text { stability }\end{array}$ \\
\hline$[5]$ & 1 & $3.1-13.3$ & 8.2 & 124.39 & FR4, 4.4 & $0.0165 \lambda_{0}$ & $0.103 \lambda_{0}$ & $45^{\circ}$ \\
\hline$[11]$ & 2 & $2.98-10.86$ & 6.92 & 113.87 & $\begin{array}{c}\text { AD300A \& AD600, } \\
3 \& 6.15\end{array}$ & $0.02 \lambda_{0}$ & $0.064 \lambda_{0}$ & $60^{\circ}$ \\
\hline$[12]$ & 2 & $3.85-11.23$ & 7.54 & 122 & FR4, 4.4 & $0.163 \lambda_{0}$ & $0.193 \lambda_{0}$ & - \\
\hline$[13]$ & 1 & $2.6-11.1$ & 6.5 & 130.77 & FR4, 4.4 & $0.0138 \lambda_{0}$ & $0.095 \lambda_{0}$ & - \\
\hline$[18]$ & 1 dual sided & $4.71-12.41$ & 8.56 & 89.95 & FR4, 4.4 & $0.025 \lambda_{0}$ & $0.33 \lambda_{0}$ & $60^{\circ}$ \\
\hline$[21]$ & 1 & $3.87-11.4$ & 7.63 & 98.69 & FR4, 4.3 & $0.02 \lambda_{0}$ & $0.18 \lambda_{0}$ & $45^{\circ}$ \\
\hline$[23]$ & 1 dual sided & $5-16.5$ & 10.75 & 107 & FR4, 4.4 & $0.026 \lambda_{0}$ & $0.18 \lambda_{0}$ & $60^{\circ}$ \\
\hline$[24]$ & 1 dual sided & $4.6-16$ & 8.7 & 131.03 & FR4, 4.4 & $0.0245 \lambda_{0}$ & $0.153 \lambda_{0}$ & $60^{\circ}$ \\
\hline Proposed & 1 & $2.39-13.67$ & 8.04 & 141 & FR4, 4.4 & $0.0127 \lambda_{0}$ & $0.138 \lambda_{0}$ & $60^{\circ}$ \\
\hline
\end{tabular}

Tab. 3. Performance comparison of the proposed UWB FSS with few existing works.

Figure 12 shows the simulated and measured comparative transmission performance of the proposed FSS at normal incidence. The measured plots have a shift in the resonant frequency with respect to the center frequency of $8 \mathrm{GHz}$ of the simulated results. The plots also show uneven edges compared to the smooth simulated plots which attribute to external reflections and inaccuracy in alignment during testing. Performance comparisons of designed FSS with few existing UWB FSS are tabulated in Tab. 3. The performance of the proposed single layer FSS is better when compared to the earlier designs in the literature with maximum bandwidth and stability.

\section{Conclusion}

A novel low-profile single layer ultra-wideband FSS is designed and the performance is experimentally validated. At normal incidence the UWB FSS offers a stop band response of $11.3 \mathrm{GHz}$ with $141 \%$ bandwidth. The FSS is stable up to $60^{\circ}$ incident angle with dual polarization. The proposed UWB-FSS can be utilized in antennas for performance enhancement and for compact wireless devices for electromagnetic shielding in stealth technology.

\section{References}

[1] MUNK, B.A. Frequency Selective Surfaces: Theory and Design. New York (USA): Wiley, 2000. ISBN: 9780471370475

[2] ABDULKAREEM, S. B., GOPALAKRISHNAN, S. Development of multilayer partially reflective surfaces for highly directive cavity antennas: a study. Wireless Communications and Mobile Computing, 2020, p. 1-14. DOI: 10.1155/2020/9578031

[3] ANWAR, R. S., MAO, L., NING, H. Frequency selective surfaces: A review. Applied Sciences, 2018, vol. 8, no. 9, p. 1-46. DOI: 10.3390/app 8091689

[4] RASHID, A. K., LI, B., SHEN, Z. An overview of threedimensional frequency-selective structures. IEEE Antennas and Propagation Magazine, 2014, vol. 56, no. 3, p. 43-67. DOI: 10.1109/map.2014.6867682
[5] SAMPATH, S. S., SIVASAMY, R. A. Single-layer UWB frequency-selective surface with band-stop response. IEEE Transactions on Electromagnetic Compatibility, 2020, vol. 62, no. 1 , p. 276-279. DOI: $10.1109 /$ temc.2018.2886285

[6] CHATTERJEE, A., PARUI, S. K. A dual layer frequency selective surface reflector for wideband applications. Radioengineering, 2016, vol. 25 , no. 1, p. 67-72. DOI: 10.13164/re.2016.0067

[7] RADONIĆ, V., CRNOJEVIĆ-BENGIN, V., SCHOEMAN, D., et al. Multi-layer frequency selective surfaces with wideband response and their modelling. In 22nd Telecommunication Forum TELFOR. Belgrade (Serbia), 2014, p. 757-760. DOI: 10.1109/TELFOR.2014.7034517

[8] TAYLOR, P. S., BATHELOR, J. C., PARKER, E. A. A passively switched dual-band circular FSS slot array. In Proceedings of the 5th European Conference on Antennas and Propagation (EUCAP). Rome (Italy), 2011, p. 507-510. DOI: 10.1109/APWC.2011.6046790

[9] ESPARZA-AGUILAR, T. E., RODRIGUEZ-CUEVAS, J., MARTYNYUK, A. E., et al. Switchable ring slot frequency selective surfaces with low-disruptive bias circuits. In International Symposium on Antennas and Propagation (APSURSI). Fajardo (Puerto Rico, USA), 2016, p. 775-776. DOI: 10.1109/APS.2016.7696096

[10] DÖKEN, B., KARTAL, M. An active frequency selective surface design having four different switchable frequency characteristics. Radioengineering, 2019, vol. 28, no. 14, p. 114-120. DOI: $10.13164 /$ re.2019.0114

[11] UNALDI, S., TESNELI, N. B., CIMEN, S. A novel miniaturized polarization independent frequency selective surface with UWB response. Radioengineering, 2018, vol. 27, no. 4, p. 1012-1017. DOI: $10.13164 /$ re.2018.1012

[12] RANGA, Y., MATEKOVITS, L., WEILY, A. R., et al. A lowprofile dual-layer ultra-wideband frequency selective surface reflector. Microwave and Optical Technology Letters, 2013, vol. 55 , no. 6 , p. 1223-1227. DOI: $10.1002 /$ mop. 27583

[13] ABDUlhasan, R. A., Alias, R., RAMli, K. N., et al. High gain CPW-fed UWB planar monopole antenna-based compact uniplanar frequency selective surface for microwave imaging. International Journal of $R F$ and Microwave Computer-Aided Engineering, 2019, vol. 29, no. 8, p. 1-15. DOI: $10.1002 /$ mmce. 21757

[14] KUNDU, S., CHATTERJEE, A., JANA, S. K., et al. A Compact umbrella-shaped UWB antenna with gain augmentation using frequency selective surface. Radioengineering, 2018, vol. 27, no. 2 , p. $448-454$. DOI: $10.13164 /$ re.2018.0448 
[15] PAZOKIAN, M., KOMJANI, N., KARIMIPOUR, M. Broadband RCS reduction of microstrip antenna using coding frequency selective surface. IEEE Antennas and Wireless Propagation Letters, 2018, vol. 17, no. 8, p. 1382-1385. DOI: 10.1109/LAWP.2018.2846613

[16] SHANG, Y., XIAO, S., WANG, B.-Z. Radar cross-section reduction design for a microstrip antenna. Microwave and Optical Technology Letters. 2014, vol. 56, no. 5, p. 1200-1204. DOI: 10.1002/mop. 28288

[17] YADAV, S., JAIN, C. P., SHARMA, M. M. Polarization independent dual-bandpass frequency selective surface for WiMax applications. International Journal of $R F$ and Microwave Computer-Aided Engineering, 2018, vol. 28, no. 6, p. 1-7. DOI: 10.1002/mmce. 21278

[18] SOOD, D., TRIPATHI, C. C. Polarization insensitive compact wide stopband frequency selective surface. Journal of Microwaves, Optoelectronics and Electromagnetic Applications, 2018, vol. 17, no. 1, p. 53-64. DOI: 10.1590/2179$10742018 \mathrm{v} 17 \mathrm{i} 11128$

[19] YAHYA, R., NAKAMURA, A., ITAMI, M., et al. A novel UWB FSS-based polarization diversity antenna. IEEE Antennas and Wireless Propagation Letters, 2017, vol. 16, p. 2525-2528. DOI: 10.1109/LAWP.2017.2730161

[20] HUA, B., HE, X., H., YANG, Y. Polarisation-independent UWB frequency selective surface based on $2.5 \mathrm{D}$ miniaturised hexagonal ring. IET Electronic Letters, 2017, vol. 53, no. 23, p. 1502-1504. DOI: $10.1049 / \mathrm{el} .2017 .2921$

[21] SIVASAMY, R., MOORTHY, B., KANAGASABAI, M., et al. Polarization-independent single-layer ultra-wideband frequencyselective surface. International Journal of Microwave and Wireless Technologies, 2017, vol. 9, no. 1, p. 93-97. DOI: $10.1017 / \mathrm{S} 1759078715001439$

[22] ZABRI, S. N., CAHILL, R., SCHUCHINSKY, A. Polarisation independent split ring frequency selective surface. IET Electronic Letters, 2013, vol. 49, no. 4, p. 245-246. DOI: $10.1049 / \mathrm{el} .2012 .4428$

[23] BISWAS, A. N., BALlaV, S., CHATTERJEE, A., et al. Evolution of low-profile ultra-wideband frequency selective surface with a stable response and sharp roll off at lower band for $\mathrm{C}, \mathrm{X}$ and $\mathrm{Ku}$ band applications. Radioengineering, 2020, vol. 29, no. 3, p. 494-503. DOI: $10.13164 /$ re.2020.0494

[24] MAJIDZADEH, M., GHOBADI, C., NOURINIA, J. Ultra-wide band electromagnetic shielding through a simple single layer frequency selective surface. Wireless Personal Communications, 2017, vol. 95, no. 3, p. 2769-2783. DOI: 10.1007/s11277-0173960-6
[25] SOHAIL, I., RANGA, Y., ESSELLE, K. P., et al. A frequency selective surface with a very wide stop band. In The $7^{\text {th }}$ European Conference on Antennas and Propagation (EuCAP). Gothenburg (Sweden), 2013, p. 2146-2148. ISBN: 978-88-907018-3-2

[26] LANGLEY, R. J., PARKER, E. A. Equivalent-circuit model for arrays of square loops. IET Electronic Letters, 1982, vol. 18, no. 7, p. 294-296. DOI: 10.1049/el:19820201

[27] KUSHWAHA, N., KUMAR, R., KRISHNA, R. Design and analysis of new compact UWB frequency selective surface and its equivalent circuit. Progress In Electromagnetic Research C, 2014, vol. 46, p. 31-39. DOI: 10.2528/PIERC13100908

[28] VARKANI, A. R., FIROUZEH, Z. H., NEZHAD, A. Z Equivalent circuit model for array of circular loop FSS structures at oblique angles of incidence. IET Microwaves, Antennas and Propagation, 2018, vol. 12, no. 5, p. 749-755. DOI: 10.1049 /ietmap.2017.1004

\section{About the Authors ...}

Sapna BIJIMANZIL ABDUL KAREEM (1979) received her B.E. degree in Electronics and Communication Engineering from Madras University-India in 2000, and M.E. degree in Communication Systems from Anna University-India in 2007. She is currently pursuing Ph.D. in the field of antennas at PSG College of Technology-India, (Affiliated to Anna University). Her research interests include planar antenna with frequency selective surface (FSS) and defected ground structure (DGS), and microwave engineering.

Srivatsun GOPALAKRISHNAN received his Bachelor's degree in Electronics and Communication Engineering from Bharathiar University, Coimbatore-India, and Master's degree in Wireless Technologies (ECE) and Ph.D. from Anna University, Chennai, India. His focus on research areas are antennas, RF devices, microwave antennas. He has widely contributed to the international and national journals publishing numerous research papers. He has been honored by AICTE-New Delhi, India with the prestigious Career Award for Young Teachers. He has also visited USA for a collaborative research work at University of Dayton. 